\title{
Psicanálise E Política: Da Mais-VAlia \\ AO MAIS-DE-GOZAR
}

\section{Luciano Elia1}

\section{Resumo}

Neste artigo, o autor visa estabelecer as bases para uma articulação entre Psicanálise e Política que tenha a possibilidade de ser rigorosa. Para isso, faz um percurso preliminar por vários elementos constitutivos do que se pode chamar, com Lacan de discurso psicanalítico, expressão que conjuga as dimensões teóricoconceitual e a ético-clínica e metodológica em um só termo, partindo da condição extraterritorial da psicanálise em relação a outros saberes mas também à própria ordem social e cultural, discutindo as relações da psicanálise com a ciência para, no final, propor, a partir dos avanços lacanianos sobre o gozo, feitos após a virada do seminário XVII, particularmente do conceito de mais-de-gozar, plasmado sobre 0 conceito marxiano de mais-valia, estabelecer uma distinção entre essas duas categorias, propondo assim um tratamento possível do capitalismo pela psicanálise.

PalaVRas-Chave: Psicanálise; Política; Mais-Valia; Mais-de-Gozar; Capitalismo

1 Psicanalista, membro do Laço Analítico/Escola de Psicanálise, Professor titular, Chefe do Departamento de Psicanálise e Coordenador do Programa de Mestrado Profissional em Psicanálise e Políticas Públicas do Instituto de Psicologia da UERJ. 
O título deste escrito traz a articulação da psicanálise com a política por um viés interdiscursivo que procura estabelecer uma ponte entre Marx e Lacan, entre marxismo e psicanálise, indo da mais-valia ao mais-de-gozar. Para isso, faremos um primeiro breve percurso que parte da posição eminentemente extraterritorial - e as vezes eu prefiro chamar de transterritorial - que a psicanálise ocupa entre os saberes e práxis. Esta termo e esta noção de extraterritorialidade é utilizada por Lacan no seu escrito "Variantes do tratamento padrão" (LACAN: 1955, 325) para caracterizar a posição da psicanálise entre os saberes e práticas, e recorre para isso à metáfora do morcego (ele chama de questão-morcego) (Ibid, 323): tal como este mamífero alado, que entre os pássaros é segregado como um mamífero roedor, um rato com asas, e entre os ratos é considerado um pássaro, a psicanálise não encontra seu lugar em nenhum campo que não seja o seu, ela é um campo sui generis, conjunto unitário, gênero de elemento único.

Podemos afirmar que, por força de seus conceitos mais fundamentais, a psicanálise não se perfila nas balizas dos saberes instituídos no campo científico e cultural que, assim, não se aplicam a ela, o que poderia nos fazer supor algum grau de extraterritorialidade. Entretanto, o que determina esta posição da psicanálise não é o seu caráter total ou eminentemente estrangeiro ao campo civilizatório ou às demais ciências, mas a vocação da psicanálise em situar-se no plano da causa, do fundamento não-representável de toda representação possível, o que só se alcança a partir do que se apresenta no campo mesmo do representável.

\footnotetext{
...diversamente as ciências humanas que, voltando-se embora para o consciente, permanecem sempre no espaço do representável, a psicanálise avança para tomar o passo à representação, galgá-la do lado da finitude... $E$ nessa região onde a representação fica em suspenso, à beira de si mesma, aberta de algum modo sobre o "fechamento" da finitude, desenham-se as três figuras pelas quais a vida, com as suas funções e as suas normas, vem fundar-se na muda representação da Morte, os conflitos e regras na abertura desnudada do Desejo, as significações e os sistemas numa linguagem que é ao mesmo tempo Lei. [...] Sabe-se como psicólogos e filósofos chamaram tudo isso: mitologia freudiana. Era bem necessário que este procedimento de Freud lhes tivesse parecido tal: para um saber que se aloja no representável, o que margina e define no exterior a possibilidade mesma da representação não pode ser senão uma mitologia. Mas quando se segue, no seu próprio curso, o movimento da psicanálise, quando se percorre o espaço epistemológico no seu conjunto, vê-se bem que essas figuras - imaginárias por certo para um olhar míope - são as formas mesmas da finitude tal como é analisada no pensamento moderno: não é porventura a Morte aquilo a partir do que o saber geral é possível, de tal maneira que seria, no tocante à psicanálise, a figura desse redobramento empírico-transcendental que
} 
caracteriza na finitude o modo de ser do homem? Não é acaso o Desejo o que permanece sempre impensado no âmago do pensamento? E essa LeiLinguagem (a um tempo palavra e sistema da palavra) que a psicanálise se esforça por fazer falar não será aquilo em que toda significação adquire uma origem mais longínqua que ela mesma, mas também aquilo cujo retorno é prometido no próprio ato da análise? É bem certo que nem essa Morte, nem esse Desejo, nem essa Lei podem encontrar-se no interior do saber que percorre na sua positividade o domínio empírico do homem; mas a razão disso está em que esta tríade designa as condições de possibilidade de todo o saber sobre o homem". (FOUCAULT: 1966, 84)

A longa citação de Foucault deixa claro que a posição extraterritorial da psicanálise se fundamenta na radicalização das condições mesmas de constituição do território a que ela está referida.

Lacan, no início da Lição V do seu Seminário X, sobre $A$ angústia, afirma: "Não é culpa minha, como se diz, se a psicanálise põe em causa no plano teórico o desejo de conhecer, e se, em seu discurso, ela se coloca em um aquém de si mesma que precede o momento do conhecimento." (LACAN: 2004, p. 69).

A Psicanálise tem um campo, um território epistêmico e metodológico que lhe são próprios, aliás radicalmente próprios, e, quando incide, afeta ou atravessa, e sofre incidências, é afetada ou atravessada por outros campos discursivos, mantém, contudo, os eixos discursivos que a definem e constituem.

Este tipo de efeito recíproco não deve, portanto, ser confundido com qualquer espécie de adaptação ou "culturalismo". Um exemplo disso é a famosa questão do freudo-marxismo. A Escola de Frankfurt, que atualizou o marxismo nos anos 20 e 30 na Alemanha, acompanhando a ascensão do nazismo, foi marcantemente afetada pelo pensamento de Freud. Uma certa tendência culturalista resultou desta articulação, como em Erich Fromm, como se, ao voltar-se para as questões da civilização e da sociedade humana, os conceitos psicanalíticos devessem relativizarse, proceder ao famoso revisionismo, perdendo seu vigor e contundência. O maior ícone da psicanálise na Escola de Frankfurt, Herbert Marcuse, entendeu por exemplo que para articular-se com a civilização a psicanálise deveria amputar-se da pulsão de morte, afirmando apenas Eros no plano das pulsões. Grosso modo, é isto "Eros e civilização" (MARCUSE, 1965 [1967]), sua mais famosa obra, de 1955. E foi justamente Theodor Adorno, que não era psicanalista, quem pôde advertir quanto aos desastrosos equívocos do revisionismo culturalista, apontando o risco de que a psicanálise perdesse a virulência de seus conceitos mais importantes. 
Para os revisionistas, a teoria das pulsões é uma excrescência biologista herdada do século XIX. A psicanálise é dessexualizada. Em vez da libido, os revisionistas falam de impulsos, necessidades, paixões. Para Adorno, essa dessexualização implica a emasculação da Psicanálise. [...] Ao suprimir a libido, o revisionismo abre mão de qualquer possibilidade de crítica ideológica. [...] O que é derivado é apresentado como primário. No mesmo instante em que a política de extermínio dos nazistas fornecia a prova mais sinistra do caráter sexual de fenômenos como o sadismo, os revisionistas falavam da "vontade de poder", associada a impulsos de medo e vingança". (ROUANET: 2003, 132)

Cuidemos, portanto, de manter os eixos do pensamento psicanalítico quando atravessamos territórios discursivos contíguos, conexos, em conflito ou em harmonia com o nosso.

Agrada-me muito pensar, por exemplo, que a proposta de uma prática rigorosa da psicanálise fora dos espaços culturais socialmente configurados pela burguesia resumidamente, o consultório privado - não se fundamenta em um libelo que apregoe a acessibilidade e a inclusão dos desfavorecidos por motivações meramente ideológicas. São princípios, eixos, coordenadas discursivas que impõem a radical indiferença do modus operandi da práxis psicanalítica a um considerável número de atributos ou qualidades sociais identificatórias (econômicas, culturais, etnográficas). A estrutura assemântica e desqualificada do inconsciente impõe a transversalidade desta práxis por todo o espectro social. Impõe, portanto, a desmontagem sistemática e estrutural de todo elitismo em psicanálise. Toda forma de elitismo deixa de ser assim apenas o fruto de uma distorção ideológica de base capitalista para tornar-se também e sobretudo uma impropriedade metodológica e discursiva. Acrescente-se a esse estatuto desvalorativo e, portanto, transversal do inconsciente seu caráter transindividual. $\mathrm{O}$ inconsciente tem aversão a qualidades e à noção mesma de indivíduo. No prefixo que compõe sua designação - in-consciente - já se inscreve a divisão que torna vão o mesmo prefixo usado em outra palavra: in-divíduo, uno, sem divisão, lugar, para Freud, de uma qualificação libidinal fálico-narcísica fundamental na identificação imaginária e eminentemente ilusória, ainda que necessária à relação do sujeito com seus semelhantes e com a realidade dos objetos amorosos.

Há neste ponto um risco que consiste em, recusando o eixo do indivíduo, sejamos atraídos pelo eixo dos grupos. Risco fundado no erro grosseiro de não perceber que grupo e indivíduo são farinha do mesmo saco, unidos no título da obra de Freud "Psicologia das massas e análise do eu" (FREUD, 1969 [1921]). Nas massas 
ou nos grupos, é do eu que se trata, sempre. O que está do outro lado da trincheira indivíduo-grupo é uma concepção e uma lógica da fragmentação, dos cacos, da coleção de traços, signos ou marcas que formam a trama do tecido do sujeito do inconsciente, sempre de estrutura coletiva (no sentido de coleção e de coletivo mesmo, se tivermos o cuidado de distinguir coletivo de grupo, (cuidado hoje redobrado, pois o termo coletivo já se banalizou de tal maneira que já não quer dizer quase mais nada de peculiar ou diverso dos grupos). Mas penso no conceito introduzido por Jean Oury nos anos 80 do século XX, em seu trabalho magnífico na Clínica de La Borde tratando de esquizofrênicos com a psicanálise (OURY, 2005 [1984-85]).

O estatuto do inconsciente, por não comportar qualidades ou valores, não poderia ser, de modo algum, privado, na medida em que, no campo social, o que é privado se caracteriza exatamente por possuir atributos e qualidades. Nesse sentido, o inconsciente não pode ser para só alguns, ou para poucos, mas só admite, logicamente, ser para todos. Sabemos que não todos farão a experiência do inconsciente, que requer determinadas condições estruturais definidas pelo dispositivo freudiano. Mas o que sustentamos é que tais condições não podem incluir a priori valorativos determinados pelas qualidades sociais e culturais. Não é possível, freudianamente falando, estabelecer que a experiência do inconsciente só é possível em determinados meios sociais, mediante determinadas condições de pagamento, com determinado nível de instrução. Sempre que Freud enveredou por considerações deste tipo - que, para ele, envolviam até a idade do analisante - ele estava mais preocupado em não fazer da psicanálise uma panaceia universal que servisse para todos os casos e com isso perder a credibilidade do meio científico, cuja aprovação era uma exigência para ele, do que em estabelecer critérios lógicos de elegibilidade dos possíveis analisantes.

Isso fica muito claro em vários escritos dele, entre os quais cito o inevitável "Caminhos da terapia psicanalítica" (FREUD, 1989 [1919]), título que os tradutores em português, sempre seguindo os passos de seus guias ingleses (a Edição Standard Brasileira é a Standard Edition em português), decidiram recalcar e fazer retornar como Linhas de progresso na terapia psicanalítica, quando o termo usado por Freud - Wege - não contém e não remete, nem de longe, nem a linha nem a progresso, mas significa caminho mesmo! Neste texto fica claro que se a psicanálise só vinha sendo 
aplicada às classes mais favorecidas, isso não passava de uma circunstância ligada à sobrevivência do psicanalista, que tira seu ganha-pão do seu trabalho clínico, circunstância que não é tão irrelevante metodologicamente por parecer meramente ligada aos interesses de uma classe profissional, mas que justamente demarcam uma relevante desconexão da prática psicanalítica com a institucionalidade estatal ou acadêmica.

Esta desconexão entre a psicanálise e os marcos reguladores e profissionalistas da ordem social civilizada implica uma importante independência da prática psicanalítica em relação às instituições sociais mas sobretudo em relação ao mundo do capital, o chamado mercado. O próprio valor das sessões não pode, a rigor, ser regulado pelo mercado. Freud, como sempre certeiro em suas formulações dialéticas, diz: "o psicanalista não discute que o dinheiro serve para a sobrevivência e obtenção de poder, mas sustenta que, ao lado disso, poderosos fatores sexuais estão implicados no valor que o dinheiro assume" (LACAN, 1969 [1913] p. 173). Constatase a obviedade e a objetividade positivista da realidade imediata mas apenas para nela introduzir o que não é nem óbvio nem factual, mas concerne ao plano da verdade: se dinheiro é importante para viver (e ter poder!), o que é poderoso no nível da verdade é seu valor libidinal, sexual, que será em Lacan retomado como o dinheiro em seu estatuto de gozo.

Ora, se é assim, como deixar que o mercado financeiro regule quanto cada um paga por seu sintoma, e o modo como paga? Claro que sabemos que os psicanalistas não conduzem com todo esse rigor a sua prática, e a maioria absoluta segue regulações de mercado, mas isso não invalida o que consta dos princípios freudianos, aos quais a prática dos psicanalistas deveria estar mais seriamente submetida, e se não está, problema a resolver, não princípios a alterar. Se a psicanálise nunca pode ser gratuita, porquanto o custo (em quantia de dinheiro ou outro) Ihe é inerente, ela, na mesma medida, nunca pode ser inacessível à maior parcela da população, a mais pobre, por implicar em custos proibitivos a esta parcela. As condições que decidem se alguém fará ou não a experiência da análise são outras, contingenciadas pelo movimento do sujeito na transferência, e, portanto, pelo desejo do psicanalista, a contrapartida que antecede e convoca a transferência do lado do psicanalista.

E como tocamos no ponto da transferência, convém lembrar que ela tampouco é privilégio de alguns sujeitos classificados a priori por critérios estranhos ao 
inconsciente. A transferência está colocada para todo sujeito, na medida em que todo sujeito se constitui em sua relação com a alteridade, na dimensão de um laço social, e não a partir de fatores internos, sejam eles de ordem biológica (endógenos, neurocerebrais ou fisiológicos), sejam derivados de alguma condição psíquica constitucional, psiquismo, alma, racionalidade inata ou outra, que faria pensar no absurdo de um sujeito "autóctone", auto-engendrado. A transferência é, assim, o movimento social do inconsciente, desde que associemos ao social (relação do sujeito com o Outro) a dimensão do íntimo. O íntimo não é o privado. $O$ inconsciente quer dizer que existe um íntimo no público, um íntimo que nada tem a ver com a privacidade das relações socialmente codificadas pela burguesia, por exemplo, mas que o sujeito, qualquer um, apela por um espaço inter-relacional em que sua intimidade, aquele que é dele próprio desconhecida, encontre as vias de exteriorização, já que sua procedência foi externa, alteritária, veio de fora.

Sabemos que a ciência, não a contemporânea, sem rigor científico algum, centrada no eixo neuro-comportamental e da "saúde" como sustentáculo da mais rentável indústria planetária, que é a de fármacos, mas a ciência clássica, que tinha a Física e não a Neurociência comportamental como modelo, séria e rigorosa, não comportava em seu campo o sujeito que, segundo uma concepção lacaniana chamada de "doutrinal de ciência" e que se impôs a Lacan por força do discurso psicanalítico e não como uma excursão epistemológica diletante, foi no entanto por ela mesma, ciência, constituído no mundo do saber. Diremos que a ciência, quando séria e rigorosa, é a inteligência sem transferência, e que a psicanálise é o fruto do acréscimo da dimensão da transferência à racionalidade da ciência. Incons/ciência, se quisermos quebrar o significante e produzir um sentido novo. Quando a ciência é apenas a gueixa servil do capitalismo, a conversa é outra.

E por falar em capitalismo, o que pode a psicanálise em relação a ele? Qual a posição da psicanálise em relação ao capitalismo? De maneira análoga àquela pela qual situamos, com Foucault, no início deste ensaio, a psicanálise em relação a outros saberes e à ordem social, ou seja, nos confins extrínsecos ao campo das representações, mas que concernem justamente às condições de representabilidade, podemos dizer que a psicanálise analisa a estrutura do capital através do conceito de gozo, cujo tratamento se tornou possível pela introdução da categoria de discurso, 
feita por Lacan a partir do Seminário XVI, “De um Outro ao outro”, dos anos 1968/69, que já mencionamos.

Para situar melhor isso, terei que me deter um pouco neste processo, interno ao ensino de Lacan. Podemos dizer que um grande ciclo inicial de seu ensino consistiu na varredura, absolutamente necessária, de todo psicologismo, biologismo e positivismo pelos quais a psicanálise estava gravemente infectada a partir do desparecimento de Freud, com os chamados pós-freudianos.

O recurso ao estruturalismo, movimento decisivo e crucial de cujas águas Lacan se serviu fartamente sem contudo nele embarcar de vez, à Linguística de Ferdinand de Saussure com a categoria de significante para conceber de modo mais rigoroso o inconsciente freudiano como transindividual e assemântico, mas sobretudo à noção de significante pensada pelos estoicos na era pré-socrática, que o situa como princípio ativo, verbal e não substantivo, da fundação do sujeito como um ato, à razão dialética, hegeliana, que retifica qualquer psicologismo intra-individualista, aos esquemas da Ótica para representar as funções imaginárias do eu, enfim, tudo isso compôs um enquadre que cumpriu sua função de despsicologizar e despositivizar a experiência e a elaboração teórica psicanalíticas.

Podemos dizer que este ciclo iniciou-se nos anos 30, quando Lacan chegou à Psicanálise através de sua tese sobre a paranoia (LACAN, 1975 [1932]) e do movimento surrealista, interrompeu-se durante a II Guerra, quando Lacan recusou-se a produzir o que quer que fosse em termos teóricos (não por acaso ele tinha apresentado uma primeira versão do "Estádio do espelho" no Congresso da IPA de Marienbad em 1936 e o reescreveu em 1949, na versão que está publicada nos seus Escritos) (LACAN, 1966 [1949]), recomeçando já em 1945 a escrever textos com o "Tempo lógico" (IDEM, 1966 [1945]) e estendeu-se pelos dez primeiros anos do seu Seminário iniciado em 1951 e registrado a partir de 1953. Foi um grande ciclo, em que a fala, mais do que a escrita, detinha toda a primazia e importância na experiência e na teoria, e a ordem simbólica, a ordem do significante, constituíam a referência maior do ensino de Lacan.

A partir do Seminário $X$ (não por acaso dedicado à Angústia, que citamos no início), mas sobretudo com a excomunhão da IPA que Lacan sofreu no ano seguinte, em que teria proferido um Seminário sobre os Nomes-do-pai que não durou mais do que uma aula e, já excomungado, fez seu Seminário $\mathrm{XI}$, com o título "Os quatro 
conceitos fundamentais da psicanálise" (LACAN, 1973 [1963/64]), o curso de seu ensino de rompe e sofre uma inflexão importante, que exigirá três anos de uma elaboração de três anos que mereceu de Lacan a denominação de relève logicienne, a lógica tomando o lugar de proa, antes conferido ao campo da fala e do significante. Os seminários XII, XIII e XIV compõem basicamente esse período de elaboração lógica, do qual Lacan sai com o Seminário XV, o Ato Psicanalítico, em seguida ao qual traz, no XVI, uma nova concepção de discurso, como sem palavras.

Esta virada lógica, para não me estender demais e ao mesmo tempo dizer o que é preciso para chegarmos ao ponto em que o capitalismo pôde ser analisado pela psicanálise, teve como novo norte a escrita - não há lógica falada, senão escrita - e isso levou Lacan a formular uma nova conceituação do que fez questão de denominar discurso. Acho isso interessante, pois discurso era até então o que sempre foi, uma concatenação diacrônica de palavras, uma fala concreta, embora em Foucault os termos de discurso e dispositivo já assumissem dimensões além da cadeia falada. Lacan subverte o próprio sentido que ele próprio conferia anteriormente à categoria de discurso, ao manter o mesmo termo e afirmar que a essência da teoria psicanalítica é um discurso sem palavras, na abertura mesma do Seminário (LACAN, 2006 [1968/69]), Lição I, de 13 de novembro de 1968 (dia fatídico no Brasil, em que o governo militar decretou o Al-5!), que se destaca das demais como ocupando uma seção única.

O título desta lição inaugural é "Da mais valia ao mais de gozar". Por que, ao introduzir sua nova categoria de discurso sem palavras, como um laço social escrito em quatro letras que ocupam quatro lugares, já é da mais-valia que Lacan vai tratar? A entrada do discurso sem palavras abre uma possibilidade inédita de tratar do gozo pelo discurso psicanalítico e é concomitante do recurso a Marx, à categoria de maisvalia como causa do gozo na ordem do capital.

O que é a mais-valia? É o que o capital não remunera ao trabalhador, é o trabalho não pago, não remunerado, que faz girar toda a máquina do capitalismo. É a quota não computável que excede ao lucro, causando-o desde o exterior de seus limites, não se reduzindo a ele que é, ele sim, computável, passível de representação e escrita nos livros contábeis. Onde o lucro entra como aquilo que é visado, necessariamente a mais-valia está em operação, e isso determina toda a lógica e os rumos do sistema e das sociedades capitalistas, com todas as consequências que 
conhecemos muito bem na economia, nas aberrantes distribuições de renda, na produção sistêmica da pobreza e da exclusão, da injustiça social, e consequentemente da violência social, do crime, da forma criminosa de combater o crime e, nos casos em que o sistema capitalista de degrada (vicissitude sempre iminente em sua repetição histórica e neurótica), resulta a barbárie como a que vivemos hoje no Brasil.

Se o valor da mais-valia não pode ser calculado, sabemos contudo que ela é parte integrante da organização capitalista. Segundo Marx, o processo de produção capitalista, posto em marcha para produzir lucro, só pode produzir mais-valia: mais valia que não é sinônimo de "lucro", nem de "gozo", pois o gozo se perde no processo transformado em trabalho ou em máquinas produtivas suplementares. [...] Notemos que ninguém goza no sistema capitalista: o lucro é reinvestido em um processo infinito. (Cf. Marx, Manuscritos de 1844) (LIPPI E LANDMAN, 2013, pp. 17-18)

A categoria marxiana de mais-valia é retomada por Lacan para situar de modo inédito o objeto a, causa do desejo, que já estava em seu ensino desde o Seminário $\mathrm{X}$, agora como mais-de-gozar. Lacan propõe em um texto que nunca foi publicado, mas que era dirigido ao Le monde, intitulado D'une reforme sans son trou, que a relação entre mais valia e mais de gozar não seja de analogia, mas de homologia, e situa esta homologia no nível dos diferentes processos de perda de gozo: é neste nível que a homologia se coloca, implicando diferenças.

\begin{abstract}
Mehrlust e Mehrwert denunciam, ambos, uma perda de gozo., mas não podemos identificá-los. Mehrlust, enquanto efeito de perda de gozo, torna-se causa do desejo, e acaba por recuperar o gozo em parte. Em contrapartda, a Mehrwert, como demonstra Marx, não passa de uma exploração de classe, consequência da organização capitalista, contra a qual os proletários devem lutar. [...] O mais de gozar é um gozo que se obtém de uma cessão de gozo. Gozo como "mais", como "preenchimento" mas que jamais preencherá a perda de gozo $\mathrm{O}$ mais de gozar faz gozar mantendo contudo a falta, e nesse sentido o sujeito sai da máquina alienante da busca de um gozo total, enquanto que a mais valia permanece comprimida na máquina capitalista como meio de reinvestir. [...] Na mais-valia não há resto: a máquina capitalista gira sem parar, o gozo perdido é reinvestido no processo infinito de acumulação, processo que nega a possibilidade da falta. Não é a mesma coisa com o objeto $a$, que é um resto que relança o desejo, desejo que passa pela castração e que faz o sujeito confrontar-se com sua falta. [...] Ainda que o valor da mais valia não seja calculável, ele é, na máquina capitalista, completamente engajado e tomado em conta, enquanto que o objeto a sai do campo da medida e do cálculo. No capitalismo, é o mais-mais-mais... enquanto que o desejo esbarra num menos que obstina-se a retornar (LIPPI E LADMAN, pp. 19-20)
\end{abstract}

O discurso psicanalítico produz mais-de-gozar, e o produz em perda, e a experiência psicanalítica faz dessa perda uma posição subjetiva a que se chega por escolha, não por impossibilidade de escolher outra coisa, algo como uma resignação 
com desgosto, remédio amargo que temos que tomar porque não tem outro remédio. A perda da qual o mais-de-gozar é, em si mesmo, uma forma, é uma perda consentida e, de algum modo, desejada. Isso contraria o capitalismo na mola mais importante de sua engrenagem, que é a mais-valia, também uma forma homóloga de perda, mas perda que se reinveste infinitamente na máquina, diferentemente do discurso psicanalítico, em que a perda, como resto, só pode ser relançada como perda e como falta, levando o sujeito ao desejo e não à acumulação. É bem evidente que um modo de gozo acompanha a operação do desejo, para não concluirmos com o recorrente apelo ao suposto combate ao gozo que a que a psicanálise nos convocaria.

Consentir na perda como forma de gozo (mais-de-gozar), admitindo não relançar a máquina em que alguns continuarão acumulando para que e de modo tal que a maioria viva na privação e na miséria, constitui uma forma de gozo e não sua supressão ou ausência, e é uma arma poderosa contra o capitalismo. 


\section{REFERÊNCIAS}

FOUCAULT, M. - O triedro dos saberes (capítulo X de As palavras e as coisas), in Estruturalismo - Antologia de Textos Teóricos, organizado por Eduardo Prado Coelho, Portugália Editora, Livraria Martis Fontes, 1966, pg. 84.

FREUD, S. - Psicologia das massas e análise do eu (1921), Edição Standard Brasileira das Obras Psicológicas Completas de Sigmund Freud, Rio de Janeiro, Imago Editora, 1969, Vol. XVIII.

FREUD, S. - Wege der Psychoanalytischen Therapie, (1919), in Studienausgabe, Frankfurtam-Maim, S. Fischer Verlag, 1989, aqui citada no original alemão em função do problema da tradução do título, indicado no nosso texto, acima.

LACAN, J. - Variantes de la cure-type, 1955, in Écrits, Paris, Aux éditions du Seuil, 1966, p. 325 .

LACAN, J. - Le séminaire, Livre X-L'angoisse (1962-63), Paris, Editions du Seuil, 2004, p. 69.

LACAN, J. Sobre o início do tratamento (Novas recomendações sobre a técnica da psicanálise I), [1913], in Edição Standard Brasileira das Obras Psicológicas Completas de Sigmund Freud, Rio de Janeiro, Imago Editora, 1969, Vol. XII. pg, 173.

LACAN, J. - De la psychose paranoiaque dans ses rapports avec la personnalité, ([1932] (Le François), 1975), Paris, Aux édiitons du Seuil, 1975.

LACAN, J. Le stage du miroir comme formateur de la fonction du Je telle qu'elle nous est revelée dans l'expérience psychanalytique ([1936]1949), Écrits, op. cit., 1966.

LACAN, J. Le temps logique et l'assertion de la certitude anticipée, (1945), Écrits, 1966.

LACAN, J. Le séminaire, Livre XI - Les quatre concepts fondamentaux de la psychanalyse, (1964/65), Paris, Aux édiitons du Seuil, 1973.

LACAN, J. Le séminaire, Livre XVI, D'un autre à l'Autre (1968/69), Paris, Editions du Seuil, 2006.

LIPPI, S. e Landman, P. (orgs.) - Marx, Lacan: L'acte révolutionnaire et l'acte analytique, Paris, Point Hors Ligne, Erès, 2013, p. 17-18.

MARCUSE, H. - Eros e civilização -uma interpretação filosófica do pensamento de Freud (1955), Rio de Janeiro, Zahar Editores, 1968.

ROUANET, S. P. - Adorno e a Psicanálise, in Adorno: 100 anos, número especial da Revista Tempo Brasileiro, comemorativa dos 100 anos do nascimento de Theodor WiesengrundAdorno, $\mathrm{n}^{\circ}$ 155, Rio de Janeiro, outubro/dezembro de 2003, p. 132. 
OURY, J. - Le collectif, le Séminaire de Saint Anne (1984-85), NÎmes, Champ Social Éditions, 2005. 


\section{PSychoANALYSIS AND POLITICS: To The MehrVert Fron The PLUS-DE-JOUIR}

\section{ABstract}

In this article, the author aims to lay the foundations for an articulation between psychoanalysis and politics that has the possibility of being rigorous. For this, it makes a preliminary journey through various constitutive elements of what can be called, with Lacan, the psychoanalytic discourse, an expression that combines the dimensions theoretical-conceptual and ethical-clinical and methodological in one term, starting from the extraterritorial condition of psychoanalysis in relation to other knowledge fields but also to the social and cultural order itself, discussing the relations of psychoanalysis with science and, in the end, to propose, based on the lacanian advances in jouissance, made after the turn of the seventeenth seminar, particularly the concept of plus-de-jouir, based on the marxian concept of Mehrvert, to distinguish between these two categories, thus proposing a possible treatment of capitalism by psychoanalysis.

KEYWORDS: Psychoanalysis; Politics; Mehrvert, Plus-de-Jouir; Capitalism 


\section{PSychanalyse Et PoliQUe: De Plus-Value Au Plus-De-JouiR}

\section{RÉSUMÉ}

Dans cet article, l'auteur a pour but d'établir les fondements pour une articulation entre la psychanalyse et la politique qui puisse être rigoureuse. Pour y aboutir, il fait un parcours préalable à travers plusieurs éléments constitutifs de ce qu'on peux nommer, avec Lacan, le discours psychanalytique, catégorie liant les dimensions théorique-conceptuelle et éthique-clinique et méthodologique dans un seul terme, et il part de la condition extraterritorielle de la psychanalyse face à d'autres champs de savoir mais aussi à l'ordre social et culturel lui-même, tout en interrogeant les rapports de la psychanalyse et de la science pour, ao bout de ce parcours, proposer, à partir des avancées lacaniennes sur la jouissance, faites à partir du Séminaire XVII, en particulier du concept de plus-de-jouir, forgé sur le concept marxien de plus-value, établir une distinction entre ces deux catégories, permettant ainsi de proposer un traitement possible du capitalisme par la psychanalyse.

Mots-ÉcLÉs: Psychanalyse; Politique; Plus-Value; Plus-de-Jouir, Capitalisme 
(C) 2019 Psicanálise \& Barroco em revista

http://www.seer.unirio.br/index.php/psicanalise-barroco/index

revista@psicanaliseebarroco.pro.br

Programa de Pós-Graduação em Memória Social — UNIRIO

Memória, Subjetividade e Criação

www.memoriasocial.pro.br/proposta-area.php 